\title{
Effect of microstructure on the impact toughness transition temperature of direct-quenched steels
}

\author{
Sakari Pallaspuro ${ }^{\mathrm{a}, \mathrm{c}}$, , Antti Kaijalainen ${ }^{\mathrm{a}}$, Saara Mehtonen ${ }^{\mathrm{b}}$, Jukka Kömi ${ }^{\mathrm{a}}$, Zhiliang Zhang ${ }^{\mathrm{c}}$, David Porter ${ }^{\mathrm{a}}$ \\ ${ }^{a}$ Centre for Advanced Steels Research, Materials and Production Engineering, University of Oulu, P.O. Box 4200, 90014 Oulu, Finland \\ b SSAB, P.O. Box 93, 92101 Raahe, Finland \\ ${ }^{c}$ Department of Structural Engineering, Faculty of Engineering Science and Technology, NTNU, Richard Birkelands vei 1 A, 7491 Trondheim, Norway
}

\section{ART ICLE INFO}

\section{Keywords:}

Charpy impact test

Brittle-ductile transition

Stress intensity factor

Characterisation

Grain size

Microstructure

\begin{abstract}
A B S T R A C T
A sufficient level of toughness at low temperatures is paramount for the use of structural steels intended for arctic applications. Therefore, it is important for the steel industry to identify the factors that control brittle fracture toughness. In this study, the quantitative effect of microstructure on the impact toughness transition temperature has been investigated with 18 different thermomechanically rolled and direct-quenched low-carbon ultra-high-strength steels with varying martensite and bainite contents. The steels were produced by altering their chemical composition, the finish rolling temperature and the total reduction of the prior austenite grains in the non-recrystallisation temperature regime, i.e. austenite pancaking, and characterised in terms of microstructural constituents, grain size distributions and texture as well as by using Charpy-V impact and tensile testing. It is shown for the first time that the impact toughness transition temperatures $\mathrm{T}_{28 \mathrm{~J}}$ and $\mathrm{T}_{50}$ closely follow a dynamic reference toughness, defined by yield strength and the size of the coarsest grains in the effective grain size distribution at 80th percentile. Decreasing the area fraction of $\{100\}$ cleavage planes oriented within $15^{\circ}$ of the macroscopic fracture plane by increasing austenite pancaking is also shown to improve $\mathrm{T}_{28 \mathrm{~J}}$. The best toughness is achieved with the lowest finish rolling temperatures that are nevertheless high enough to avoid the subsequent formation of granular bainite, which weakens both the toughness and strength. The results show that it is perfectly possible to produce untempered ultra-high-strength martensitic and martensitic-bainitic structural steels with adequate low-temperature toughness when the grain size is properly controlled.
\end{abstract}

\section{Introduction}

In ferritic steels at high temperatures, the dominant crack growth mechanism is microvoid coalescence, but at sufficiently low temperatures, ductile crack growth is followed by an increasing amount of brittle cleavage fracture until failure is completely brittle. In the ductile-brittle transition region in polycrystalline materials these two mechanisms can alternate due to local cleavage crack arrests, while the probability for brittle failure increases as more material is sampled during the ductile crack growth before the critically sized microcrack is encountered.

Knowledge of the toughness properties and how they evolve in the ductile-brittle transition temperature (DBTT) region is essential for safe structural design. The most widely used method to characterise the transition temperature behaviour of steels is Charpy impact toughness testing. The data from the test is normally used to define toughness at a given temperature or some certain transition temperature value, like $\mathrm{T}_{50}$, the fracture appearance transition temperature corresponding to $50 \%$ ductile fracture $\left(\mathrm{FATT}_{50}\right)$, or $\mathrm{T}_{28 \mathrm{~J}}$. $\mathrm{T}_{50}$, also referred to as the DBTT, is the temperature where the absorbed energy obtains the average of the upper and lower shelf toughness values. $\mathrm{T}_{28 \mathrm{~J}}$ (or $\mathrm{T}_{27 \mathrm{~J}}$ ) defines the impact toughness transition temperature where the fitted transition curve coincides with the given absorbed energy value. The difference between the $T_{27 \mathrm{~J}}$ and $\mathrm{T}_{28 \mathrm{~J}}$ is only in the philosophy of rounding the value in joules from $20 \mathrm{ft}-\mathrm{lb}$ and the difference in temperature is estimated to be within $1{ }^{\circ} \mathrm{C}$. The most common way to fit the scatter-ridden test data is to utilise the tanh-fitting. Other popular means to fit the data are e.g. exponential fit, which enables the use of just the lower-shelf data, and fitting by hand. [1]

The benefit of $\mathrm{T}_{28 \mathrm{~J}}$ is that it lies on the less scattered lower shelf side of the DBTT region. As opposed to $\mathrm{FATT}_{50}$, it does not rely on the

\footnotetext{
* Corresponding author at: Centre for Advanced Steels Research, Materials and Production Engineering, University of Oulu, P.O. Box 4200, 90014 Oulu, Finland.

Email addresses: sakari.pallaspuro@oulu.fi (S. Pallaspuro); antti.kaijalainen@oulu.fi (A. Kaijalainen); saara.mehtonen@ssab.com (S. Mehtonen); jukka.komi@oulu.fi (J. Kömi); zhiliang.zhang@ntnu.no (Z. Zhang); david.porter@oulu.fi (D. Porter)
} 
subjective fracture appearance determination and the fracture surfaces consist macroscopically mainly of transgranular crack propagation. A level of $27-28 \mathrm{~J}$ is low enough to mostly omit the tearing resistance dependence of the shear zone area. Also, $\mathrm{T}_{28 \mathrm{~J}}$ can be determined by covering a smaller part of the DBTT range when an appropriate fitting method is used. Furthermore, $T_{28 \mathrm{~J}}$ is important as it is the basis for the estimation of the fracture toughness reference temperature $T_{0}[2]$, which is used in structural integrity procedures [3-6], and it is commonly used as the minimum specified toughness level for many steel grades.

Of all the factors having an effect on toughness and the ductile-brittle transition temperature, grain size is the most well established, usually following a familiar Hall-Petch type equation [7-22]. Barr and Tipper [7] were the first to show with the Liberty ships that the DBTT was elevated with increasing ferrite (F) grain size. Since then, different microstructural units have been linked to toughness: ferrite grain size in ferritic-pearlitic steels $[8,9]$, while in bainitic and martensitic steels the prior austenite grain (PAG) size [10,23], packet size [10-12] and block size [13] have been claimed to be important. More generally, the effective grain size, i.e. the size of grains bound by high-angle grain boundaries has been shown to be important [14-23]. It is recognised that this effective microstructural unit governing cleavage and ductile-brittle transition in as-quenched microstructures is the block boundary between distinct Bain variants $[19,24]$ corresponding to a grain boundary misorientation of at least $15^{\circ}[25,26]$.

Historically, untempered martensite has been considered unwanted as being too brittle for structural use. Despite this, it has been shown that, in the case of sufficiently low carbon contents, combinations of as-quenched microstructural constituents including martensite can possess similar or even better low-temperature toughness properties than the conventional softer phases due to their finer effective grain size and the occurrence of autotempering due to the relatively high martensite start temperatures of low-carbon compositions [15-17,22,27]. In addition to conventional tempering, successful methods to improve the DBTT of as-quenched steels are increasing the bainite content $[17,20]$, refinement of the prior austenite grain structure $[13,16,20]$ and, in the case of direct quenching, lowering the finish rolling temperature (FRT) below the non-recrystallisation temperature $\mathrm{T}_{\mathrm{NR}}[16,20,28]$. Depending on the process parameters and the hardenability of the material, the latter two or even all three of these toughening methods are usually used in conjunction with each other. Recent studies have highlighted the importance of texture on the bendability of direct-quenched ultra-high-strength steels (UHSS) $[29,30]$ and on the impact toughness of a ferritic steel [31].

Many works have been dedicated to deriving formulae to predict the impact toughness transition temperatures of steels. In studies with ferritic-pearlitic steels Pickering and Gladman [8] linked $\mathrm{T}_{50}$ to the inverse square root of the grain size and Mintz et al. [9] included the detrimental factors of grain boundary carbides and elevated yield stress to the estimate. Effective grain size has been incorporated to the modified Mintz type equations by Bhattacharjee et al. [14] for ferritic steels and by Gutiérrez [18] extending the equation to bainitic microstructures. Isasti et al. [21] added the DBTT raising effects of M-A islands and grain size heterogeneity. Common to these estimates is that they all show that, other things being equal, elevated yield strength $\left(\sigma_{\mathrm{YS}}\right)$ reduces toughness.

A range of definitions have been used to describe the effective grain size for estimating toughness: average grain size $d_{\text {avg }}$ [14-18] and the size of the coarsest grains at various percentiles in the cumulative grain size distribution $\mathrm{d}_{80 \%}[21,22]$ or $\mathrm{d}_{90 \%}[20,28,32]$. Volume-weighted average grain size $d_{v}$ has been successfully used with heterogeneous grain size distributions to describe strength with a modified Hall-Petch equation [33] and it would be of interest to apply this to toughness analyses since it is calculated on the basis of the whole grain size distribution but gives the greatest importance to the largest grains.

The present study brings out the effects of microstructural constituents, grain size, texture and yield strength on the impact toughness transition temperatures of thermomechanically rolled and direct-quenched martensitic and martensitic-bainitic steels, thereby addressing the needs identified in a recent review [34]. These low-carbon ultra-high-strength steels, used in the as-quenched condition, are a modern economical type of structural steel with yield strengths above $900 \mathrm{MPa}$. They combine high strength with sufficient toughness, formability and weldability, and are typically used in weight-critical and high-performance structures [35]. It is shown for the first time that the transition temperatures do not correlate with yield strength alone but that, in conjunction with the area percentage of cleavage planes on the macroscopical crack plane, a simple stress-intensity term described with yield strength and effective coarse grain size is able to model the transition temperatures with good accuracy.

\section{Materials and methods}

The influence of microstructural constituents, grain size and texture on the impact toughness transition temperatures was investigated with experimentally hot-rolled and direct-quenched low-carbon steels with the chemical compositions shown in Table 1 . The carbon equivalent $\mathrm{CE}_{\text {IIW }}$ [36] is included as a rough measure of the relative hardenability of the different compositions. The data set is complemented with experimental S960 steels originally introduced in Refs. [20,30] that are further investigated here. Different microstructures were produced by varying both the finish rolling temperatures (FRT) from 950 to $800{ }^{\circ} \mathrm{C}$, thereby covering the temperature regions both above and below the non-recrystallisation temperature $\mathrm{T}_{\mathrm{NR}}$, and the total rolling reduction of the PAG below $\mathrm{T}_{\mathrm{NR}}\left(\mathrm{R}_{\mathrm{TOT}}\right)$. After the final pass, the $8 \mathrm{~mm}$ thick (S960: $6 \mathrm{~mm}$ ) strips were direct-quenched to room temperature at a rate of $50-70{ }^{\circ} \mathrm{C} / \mathrm{s}$. The 18 individual materials are denoted later by the code given in Table 1 combined with the FRT. For comparison, material S960-830 was reaustenitised and quenched, and is referred to as material S960-RQ. To be able to compare materials with differing $\mathrm{T}_{\mathrm{NR}}$, the finish rolling temperature was normalised relative to $\mathrm{T}_{\mathrm{NR}}$ using the parameter $\mathrm{FRT}_{\mathrm{N}}$ as described in Eq. (1), temperatures used here in ${ }^{\circ} \mathrm{C}$. The non-recrystallisation temperature was chosen in preference to the more appropriate recrystallisation stop temperature as $\mathrm{T}_{\mathrm{NR}}$ can be estimated on the basis of the Boratto formula given in Ref. [37], but its in-

Table 1

Chemical compositions in wt $\%$, carbon equivalent and non-recrystallisation temperatures $\mathrm{T}_{\mathrm{NR}}$.

\begin{tabular}{|c|c|c|c|c|c|c|c|c|c|c|c|c|c|}
\hline Steel & C & Mn & $\mathrm{Si}$ & $\mathrm{Cr}$ & Mo & $\mathrm{Al}$ & $\mathrm{Ti}$ & $\mathrm{Nb}$ & B & $\mathrm{P}$ & $S$ & $\mathrm{CE}_{\text {IIW }}$ & $\begin{array}{l}\mathrm{T}_{\mathrm{NR}} \\
{\left[{ }^{\circ} \mathrm{C}\right]}\end{array}$ \\
\hline A & 0.07 & 1.4 & 0.2 & 1.0 & 0.02 & 0.03 & 0.02 & 0.039 & 0.001 & 0.009 & 0.0007 & 0.50 & 987 \\
\hline B & 0.08 & 1.8 & 0.2 & 1.0 & 0.01 & 0.04 & 0.02 & 0.040 & 0.002 & 0.011 & 0.0004 & 0.59 & 997 \\
\hline C & 0.09 & 1.1 & 0.2 & 1.1 & 0.15 & 0.04 & 0.02 & 0.042 & 0.001 & 0.009 & 0.0006 & 0.54 & 1014 \\
\hline $\begin{array}{l}\text { S960 } \\
{[20,30]}\end{array}$ & 0.09 & 1.1 & 0.2 & 1.2 & 0.01 & 0.03 & 0.03 & 0.004 & 0.002 & 0.007 & 0.0020 & 0.55 & 856 \\
\hline
\end{tabular}


exactness is acknowledged.

$$
F R T_{N}=1-F R T / T_{N R}
$$

The prior austenite grain size was measured after picric acid etching using a Keyence VK-X200 laser scanning confocal microscope and the total rolling reduction of the PAG below $\mathrm{T}_{\mathrm{NR}}\left(\mathrm{R}_{\mathrm{TOT}}\right)$ was determined according to Ref. [38]. Microstructural characterisation of the transformation microstructures was performed on nital-etched specimens with a ZEISS Ultra Plus field emission scanning electron microscope (FE-SEM) to quantify the phase fractions following the microstructural classification described in Ref. [39]. Electron backscatter diffraction (EBSD) measurements and analysis were performed at the mid-thickness position on RD-ND sections to define the grain size parameters and texture using Oxford-HKL acquisition and analysis software with a $10 \mathrm{kV}$ acceleration voltage and $0.2 \mu \mathrm{m}$ step size $(0.05-0.15 \mu \mathrm{m}$ for $\mathrm{S} 960)$.

All the grain size parameters are determined as equivalent circle diameters of the grains with high-angle boundaries $\left(>15^{\circ}\right)$ excluding values smaller than $0.3 \mu \mathrm{m} . \mathrm{D}_{\mathrm{avg}}$ is the average grain size of the population, the sizes of the coarsest grains $\mathrm{d}_{80 \%}$ and $\mathrm{d}_{90 \%}$ correspond respectively to the effective grain size at $80 \%$ and $90 \%$ in the cumulative size distribution, and the volume-weighted average grain size $d_{v}$ is calculated with Eq. (2) according to Ref. [33] using unfitted data sets.

Charpy-V notch impact testing was performed according to the standard EN ISO 148-1 [40] at temperatures ranging from 40 to $-140{ }^{\circ} \mathrm{C}$ to fully and reliably characterise the transition temperature region using mainly $7.5 \mathrm{~mm}$ thick sub-size specimens, $6 \mathrm{~mm}$ thick in the case of S960, tested in both longitudinal-transverse (LT) and transverse-longitudinal (TL) orientations, which means the total data set covered 36 samples. Note that LT specimens have their long side parallel to the longitudinal (rolling) direction and their notches pointing in the transverse direction while for TL specimens the opposite is true. Tanh-fitting was used to calculate the $\mathrm{T}_{28 \mathrm{~J}}$ and $\mathrm{T}_{50}$ transition temperatures. $\mathrm{T}_{28 \mathrm{~J}}$ values are reported as their equivalent full-size values using the procedure explained in Ref. [1].

$d_{v}^{-1 / 2}=d_{\text {avg }}^{-1 / 2}\left(-0.0635 \times \frac{P_{99 \%}-P_{1 \%}}{d_{\text {avg }}}\right)$

\section{Results}

\subsection{Microstructure, texture and grain size}

The results of the microstructural and textural characterisation from the mid-thickness of the materials are summarised in Tables 2, 3. The changes in the microstructure can be best described with the process parameter $\mathrm{FRT}_{\mathrm{N}}$. The martensite content varies with $\mathrm{FRT}_{\mathrm{N}}$ and the hardenability as characterised by the carbon equivalent (Fig. 1a). The materials B920, B880 and S960-RQ are fully autotempered lath martensite (ATM) [27], while the other materials include combinations of ATM and bainite, but also $10 \%$ ferrite in the case of A820. The direct-quenched S960 variants with lower $\mathrm{FRT}_{\mathrm{N}}$ than the other steels, are the only ones where lower bainite (LB) was observed.

Fig. 1b) shows that the coarse grain size $d_{80 \%}$ is strongly influenced by the degree of pancaking, i.e. the total reduction of the PAG below the

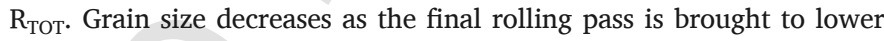
temperatures. Exceptions to this are the materials with low finish rolling temperatures where the appearance of more than $10 \%$ granular bainite (GB) causes the grain size to abruptly increase. All the different grain size definitions do evolve in a similar manner, although the changes in the average grain size $d_{\text {avg }}$ are minor.

The intensities of the texture components $\{001\}<110>$ and $\{112\}<110>$ along with the percentual area of $\{100\}$ cleavage planes and $\{112\}$ shear planes within $15^{\circ}$ of the LT and TL oriented specimens crack growth planes are shown in Table 3. Both the peak intensities and the area of cleavage planes develop with $\mathrm{FRT}_{\mathrm{N}}$ and $\mathrm{R}_{\mathrm{TOT}}$ in the same manner as the grain size: the $\{001\}<110>$ intensity and the area of $\{100\}$ planes decrease while the $\{112\}<110>$ intensity and the area of $\{112\}$ planes increase up to the point where the granular bainite formation starts to be significant. After this these trends are re-

Table 2

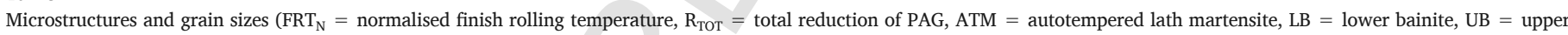

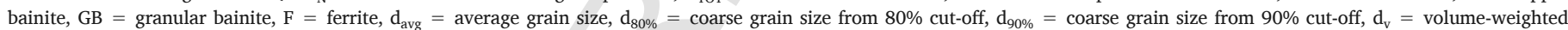
average grain size). For $d_{a v g}$ the standard error is $<0.04 \mu \mathrm{m}$.

\begin{tabular}{|c|c|c|c|c|c|c|c|c|c|c|}
\hline Material & $\mathrm{FRT}_{\mathrm{N}}$ & $\begin{array}{l}\mathrm{R}_{\mathrm{TOT}} \\
{[\%]}\end{array}$ & $\begin{array}{l}\text { ATM } \\
{[\%]}\end{array}$ & $\begin{array}{l}\text { LB } \\
{[\%]}\end{array}$ & $\begin{array}{l}\text { UB } \\
{[\%]}\end{array}$ & GB (F) [\%] & $\mathrm{d}_{\mathrm{avg}}[\mu \mathrm{m}]$ & $\begin{array}{l}d_{80 \%} \\
{[\mu \mathrm{m}]}\end{array}$ & $\begin{array}{l}\mathrm{d}_{90 \%} \\
{[\mu \mathrm{m}]}\end{array}$ & $\mathrm{d}_{\mathrm{v}}[\mu \mathrm{m}]$ \\
\hline A920 & 0.07 & 54.6 & 80 & & 20 & & 1.29 & 5.41 & 8.24 & 3.63 \\
\hline A880 & 0.11 & 62.3 & 50 & 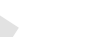 & 40 & 10 & 1.24 & 4.88 & 7.21 & 3.22 \\
\hline A840 & 0.15 & 67.4 & 10 & & 50 & 40 & 1.49 & 6.29 & 9.23 & 4.11 \\
\hline A820 & 0.17 & 65.7 & 5 & & 45 & $40(10)$ & 1.23 & 5.24 & 8.89 & 3.62 \\
\hline B920 & 0.08 & 53.2 & 100 & & & & 1.53 & 7.85 & 12.1 & 5.75 \\
\hline B880 & 0.12 & 63.1 & 100 & & & & 1.21 & 5.16 & 7.99 & 3.44 \\
\hline B820 & 0.18 & 67.0 & 90 & & 10 & & 1.09 & 4.63 & 7.75 & 3.15 \\
\hline C920 & 0.09 & 51.9 & 90 & & 10 & & 1.23 & 4.73 & 6.95 & 3.19 \\
\hline C880 & 0.13 & 63.6 & 70 & & 30 & & 1.04 & 4.04 & 6.42 & 2.69 \\
\hline C840 & 0.17 & 64.4 & 25 & & 70 & 5 & 1.05 & 3.87 & 6.16 & 2.67 \\
\hline $\mathrm{C} 820$ & 0.19 & 64.2 & 10 & & 60 & 30 & 1.34 & 5.55 & 8.23 & 3.79 \\
\hline $\mathrm{C} 800$ & 0.21 & 69.1 & 10 & & 45 & 45 & 1.54 & 6.24 & 9.30 & 4.21 \\
\hline S960-RQ & 0.00 & 0.0 & 100 & & & & 1.49 & 9.02 & 13.23 & 6.81 \\
\hline S960-950 & -0.11 & 23.0 & 96 & 4 & & & 1.39 & 6.68 & 10.18 & 4.40 \\
\hline S960-920 & -0.07 & 44.0 & 82 & 18 & & & 1.26 & 5.70 & 8.42 & 3.48 \\
\hline S960-850 & 0.01 & 56.0 & 88 & 12 & & & 1.21 & 4.63 & 6.97 & 3.09 \\
\hline S960-830 & 0.03 & 79.0 & 66 & 24 & 10 & & 1.14 & 3.41 & 5.24 & 2.41 \\
\hline S960-820 & 0.04 & 71.2 & 62 & 13 & 13 & 12 & 1.15 & 4.10 & 6.19 & 2.85 \\
\hline
\end{tabular}


Table 3

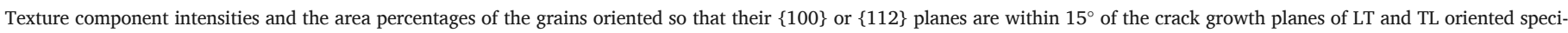
men.

\begin{tabular}{|c|c|c|c|c|c|c|}
\hline Material & $\begin{array}{l}\{001\} \\
<110>\end{array}$ & $\begin{array}{l}\{112\} \\
<110>\end{array}$ & $\begin{array}{l}\text { Area of }\{100\} \text { planes }( \pm \\
15^{\circ}, \text { LT) }[\%]\end{array}$ & $\begin{array}{l}\text { Area of }\{100\} \text { planes }( \pm \\
\left.15^{\circ}, \mathrm{TL}\right)[\%]\end{array}$ & $\begin{array}{l}\text { Area of }\{112\} \text { planes } \\
\left( \pm 15^{\circ}, \mathrm{LT}\right)[\%]\end{array}$ & $\begin{array}{l}\text { Area of }\{112\} \text { planes } \\
\left( \pm 15^{\circ}, \mathrm{TL}\right)[\%]\end{array}$ \\
\hline A920 & 2.5 & 6.2 & 6.4 & 8.2 & 27.2 & 38.5 \\
\hline A880 & 4.2 & 2.0 & 6.1 & 8.7 & 31.3 & 29.4 \\
\hline A840 & 4.2 & 6.0 & 1.6 & 5.2 & 39.6 & 34.1 \\
\hline A820 & 2.2 & 12.0 & 3.4 & 5.7 & 27.6 & 43.3 \\
\hline B920 & 3.7 & 4.5 & 5.8 & 9.0 & 28.1 & 33.0 \\
\hline B880 & 2.2 & 3.5 & 3.1 & 4.7 & 33.3 & 33.9 \\
\hline B820 & 1.8 & 7.3 & 2.9 & 6.5 & 30.8 & 35.8 \\
\hline C920 & 4.5 & 3.5 & 7.1 & 9.3 & 23.6 & 28.2 \\
\hline C880 & 3.8 & 6.5 & 4.3 & 7.4 & 28.1 & 30.7 \\
\hline C840 & 2.3 & 6.5 & 2.7 & 5.5 & 39.2 & 37.2 \\
\hline C820 & 6.0 & 5.0 & 3.3 & 4.6 & 35.8 & 34.9 \\
\hline C800 & 1.5 & 12.8 & 2.5 & 6.4 & 33.5 & 41.9 \\
\hline S960 RQ & 8.6 & 4.3 & 6.6 & 8.0 & 27.4 & 34.4 \\
\hline S960-950 & 3.8 & 1.6 & 9.6 & 9.5 & 34.2 & 36.1 \\
\hline S960-920 & 8.4 & 3.0 & 8.8 & 10.1 & 18.2 & 29.4 \\
\hline S960-850 & 2.8 & 3.6 & 7.6 & 8.7 & 29.1 & 38.3 \\
\hline S960-830 & 1.8 & 11.6 & 3.0 & 7.1 & 33.1 & 33.0 \\
\hline S960-820 & 3.8 & 6.3 & 4.1 & 6.7 & 33.5 & 31.4 \\
\hline
\end{tabular}
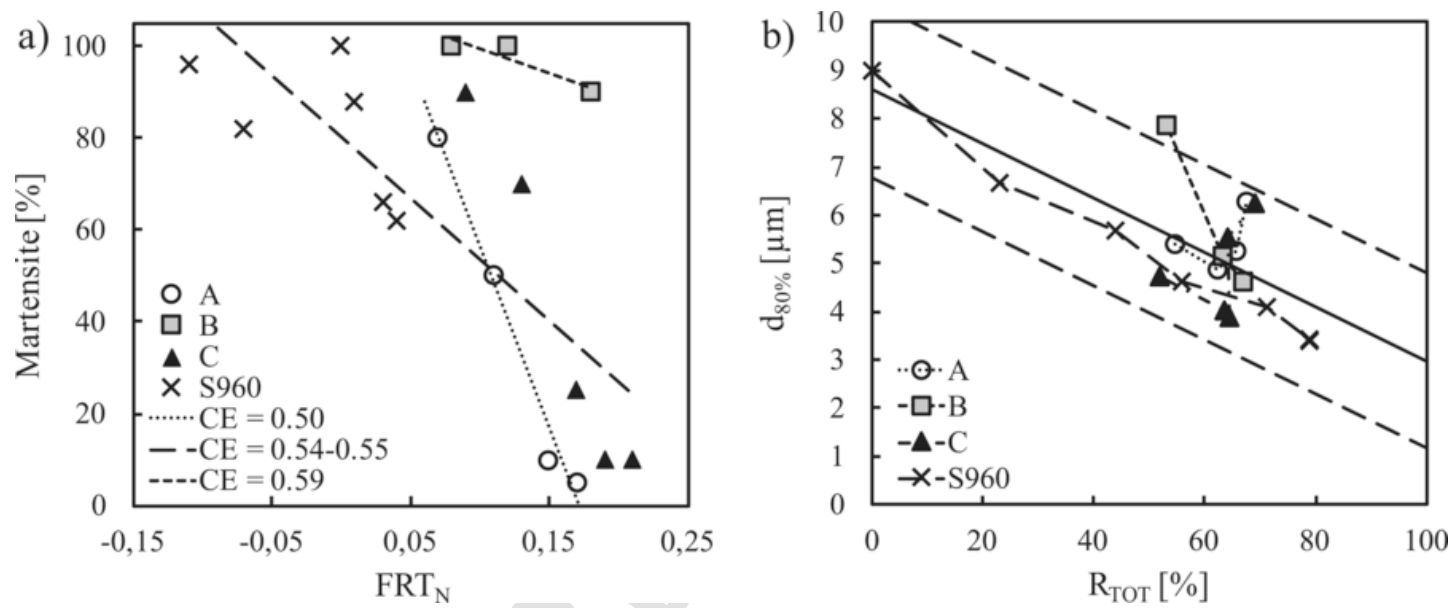

Fig. 1. a) Effect of the normalised finish rolling temperature $\left(\mathrm{FRT}_{\mathrm{N}}\right)$ on the martensite fraction, and b) effect of the austenite pancaking $\left(\mathrm{R}_{\mathrm{TOT}}\right)$ on the coarse grain size $\mathrm{d}_{80 \%}$.

versed until the GB grains are refined sufficiently. S960-RQ inherits some of its texture from the $5960-830$ from which it is reaustenitised and quenched. Both the measured $\{100\}$ and $\{112\}$ planes are more frequent in the RD-ND plane, i.e. in the crack growth plane of the TL specimen.

\subsection{Mechanical properties}

The impact toughness transition temperatures and the room temperature $0.2 \%$ offset yield strengths from Refs. [20,30] are reported in Table 4 and the ductile-brittle transition curves in Fig. 2. The standard deviation for both $\mathrm{T}_{28 \mathrm{~J}}$ and $\mathrm{T}_{50}$ is estimated as $10^{\circ} \mathrm{C}$ using the method presented in Ref. [1]. $\mathrm{T}_{28 \mathrm{~J}}$ ranges from -9 to $-126^{\circ} \mathrm{C}$ with the mainly martensitic steels B and 5960 showing higher transition temperatures. The LT and TL values of $\mathrm{T}_{28 \mathrm{~J}}$ have a very good correlation with each other (coefficient of determination $\mathrm{R}^{2}=0.92$ ) with the values being on average $4{ }^{\circ} \mathrm{C}$ higher for the TL orientation. With $\mathrm{T}_{50}$ this correlation is not as strong $\left(\mathrm{R}^{2}=0.87\right)$ and the average difference is $+6{ }^{\circ} \mathrm{C}$. Un- like the effect of specimen orientation on $\mathrm{T}_{28 \mathrm{~J}}$ and $\mathrm{T}_{50}$, the upper shelf energies are strongly affected: on average, TL specimens show $30 \%$ lower values than the LT specimens (Fig. 2). There are differences in the yield strengths measured with LT and TL specimens that vary from case to case but on average there is no significant difference between the two. A drop in yield strength is seen in the materials containing granular bainite and the material A820 has $\sigma_{\mathrm{YS}}<900 \mathrm{MPa}$ due to its low hardenability and martensite content. The best toughness is achieved in steel C, while yield strengths reach $1100 \mathrm{MPa}$ and above in the materials B820, S960-850 and S960-830. The best combination of these toughness and yield strength values is a subjective choice, but the highest absolute value $\sigma_{\mathrm{YS}} \times \mathrm{T}_{28 \mathrm{~J}}$ is achieved in the materials C880 and C840 and the lowest value in the reheated and quenched $S 960$ and in $S 960$ with the highest FRT, i.e. a negative $\mathrm{FRT}_{\mathrm{N}}$.

Martensite content has an apparent impairing effect on impact toughness transition temperature: apart from the fully martensitic microstructures, a broad range of martensite contents, i.e. between $10 \%$ and $70 \%$, can yield values of $\mathrm{T}_{28 \mathrm{~J}}$ at or below $-85{ }^{\circ} \mathrm{C}$ while retaining 
Table 4

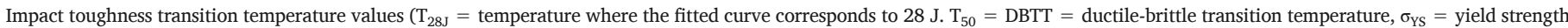
in longitudinal ( $\mathrm{L}$ ) and transverse $(\mathrm{T})$ tensile directions).

\begin{tabular}{|c|c|c|c|c|c|c|}
\hline Material & $\mathrm{T}_{28 \mathrm{~J}}(\mathrm{LT})\left[{ }^{\circ} \mathrm{C}\right]$ & $\mathrm{T}_{28 \mathrm{~J}}(\mathrm{TL})\left[{ }^{\circ} \mathrm{C}\right]$ & $\mathrm{T}_{50}(\mathrm{LT})\left[{ }^{\circ} \mathrm{C}\right]$ & $\mathrm{T}_{50}(\mathrm{TL})\left[{ }^{\circ} \mathrm{C}\right]$ & $\sigma_{\mathrm{YS}}(\mathrm{L})[\mathrm{MPa}][20,30]$ & $\sigma_{\mathrm{YS}}(\mathrm{T})[\mathrm{MPa}][20,30]$ \\
\hline A920 & -72 & -67 & -59 & -54 & $1003 \pm 3$ & $1018 \pm 1$ \\
\hline A880 & -102 & -110 & -81 & -78 & $967 \pm 12$ & $1003 \pm 6$ \\
\hline A840 & -98 & -89 & -75 & -63 & $901 \pm 37$ & $909 \pm 11$ \\
\hline A820 & -98 & -105 & -74 & -65 & $879 \pm 21$ & $849 \pm 12$ \\
\hline B920 & -44 & -39 & -35 & -31 & $1080 \pm 3$ & $1091 \pm 1$ \\
\hline B880 & -57 & -54 & -43 & -39 & $1102 \pm 2$ & $1098 \pm 3$ \\
\hline B820 & -96 & -77 & -73 & -60 & $1009 \pm 34$ & $1104 \pm 6$ \\
\hline C920 & -51 & -50 & -36 & -39 & $1057 \pm 9$ & $1059 \pm 5$ \\
\hline C880 & -100 & -127 & -77 & -94 & $1092 \pm 27$ & $1070 \pm 5$ \\
\hline C840 & -126 & -126 & -93 & -84 & $1031 \pm 46$ & $1048 \pm 14$ \\
\hline C820 & -94 & -91 & -78 & -73 & $980 \pm 17$ & $953 \pm 11$ \\
\hline C800 & -85 & -88 & -66 & -79 & $959 \pm 22$ & $943 \pm 5$ \\
\hline S960-RQ & -23 & -9 & -14 & -4 & $935 \pm 39$ & $936 \pm 12$ \\
\hline S960-950 & -17 & -9 & -19 & -10 & $1051 \pm 16$ & $1034 \pm 8$ \\
\hline S960-920 & -50 & -26 & -35 & -25 & $1059 \pm 4$ & $1052 \pm 7$ \\
\hline S960-850 & -63 & -51 & -60 & -45 & $1134 \pm 4$ & $1120 \pm 17$ \\
\hline S960-830 & -97 & -92 & -100 & -74 & $1175 \pm 19$ & $1148 \pm 3$ \\
\hline S960-820 & -109 & -98 & -96 & -97 & $982 \pm 20$ & $987 \pm 6$ \\
\hline
\end{tabular}
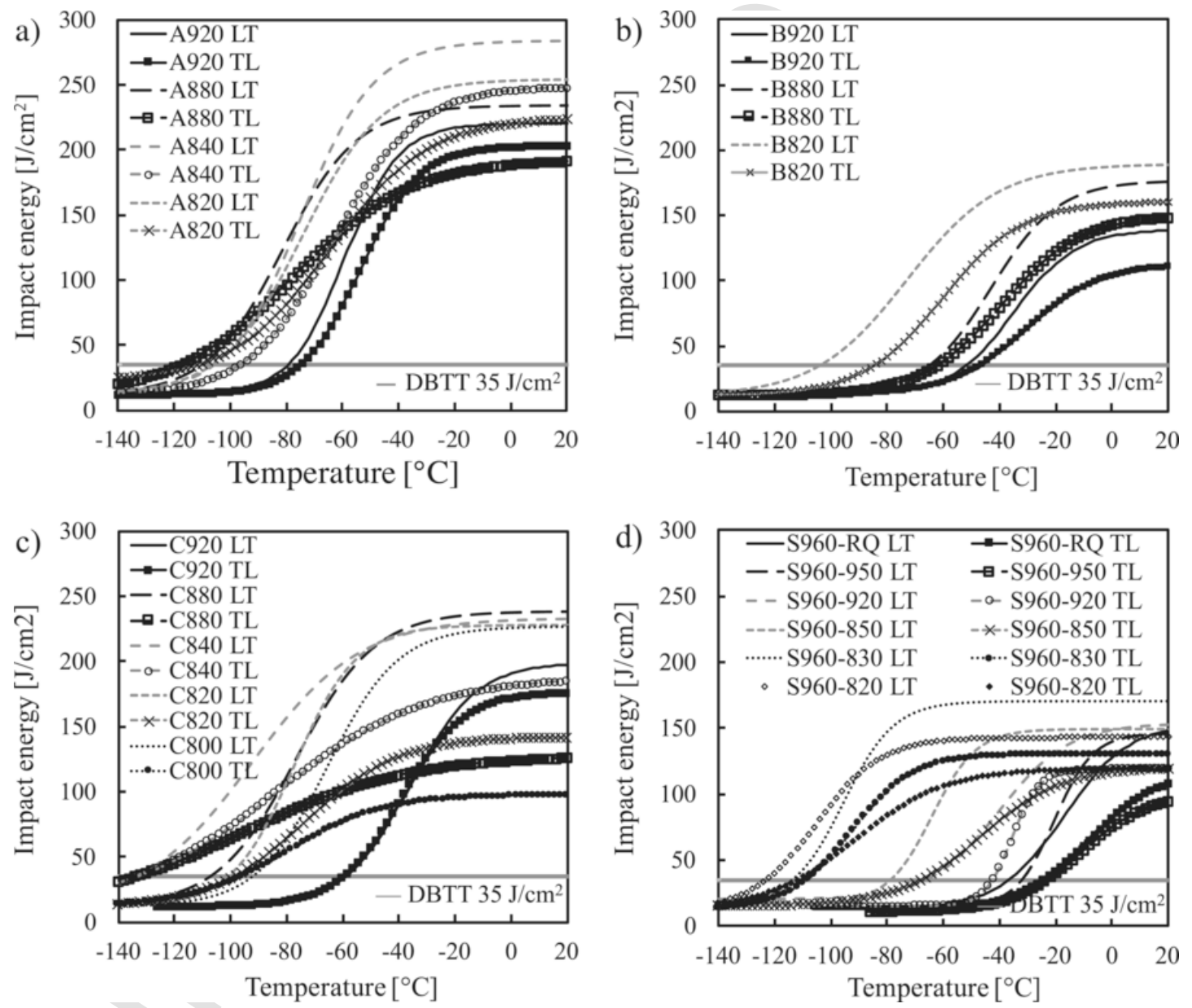

Fig. 2. Ductile-brittle transition curves of the steels A, B, C and S960 in a), b), c) and d), respectively.

yield strength $>900 \mathrm{MPa}$ (Fig. 3a). For the present materials, these low transition temperatures are obtained when the coarse grain size $\mathrm{d}_{80 \%}$ is $6.3 \mu \mathrm{m}$ or less $\left(d_{80 \%}^{-0.5} \geq 0.40\right)$, Fig. 3b). The materials of steel A and C containing more than $12 \%$ granular bainite form a separate group, with relatively low strength and above average $\mathrm{T}_{28 \mathrm{~J}}$, which nev- ertheless are inferior to those with GB $<12 \%$ and $10-70 \%$ martensite. The higher tails of the trend in Fig. 3a) can be accounted for by larger grain sizes. The overall influence of the grain size on $\mathrm{T}_{28 \mathrm{~J}}$ is clearly seen in Fig. 3b). 

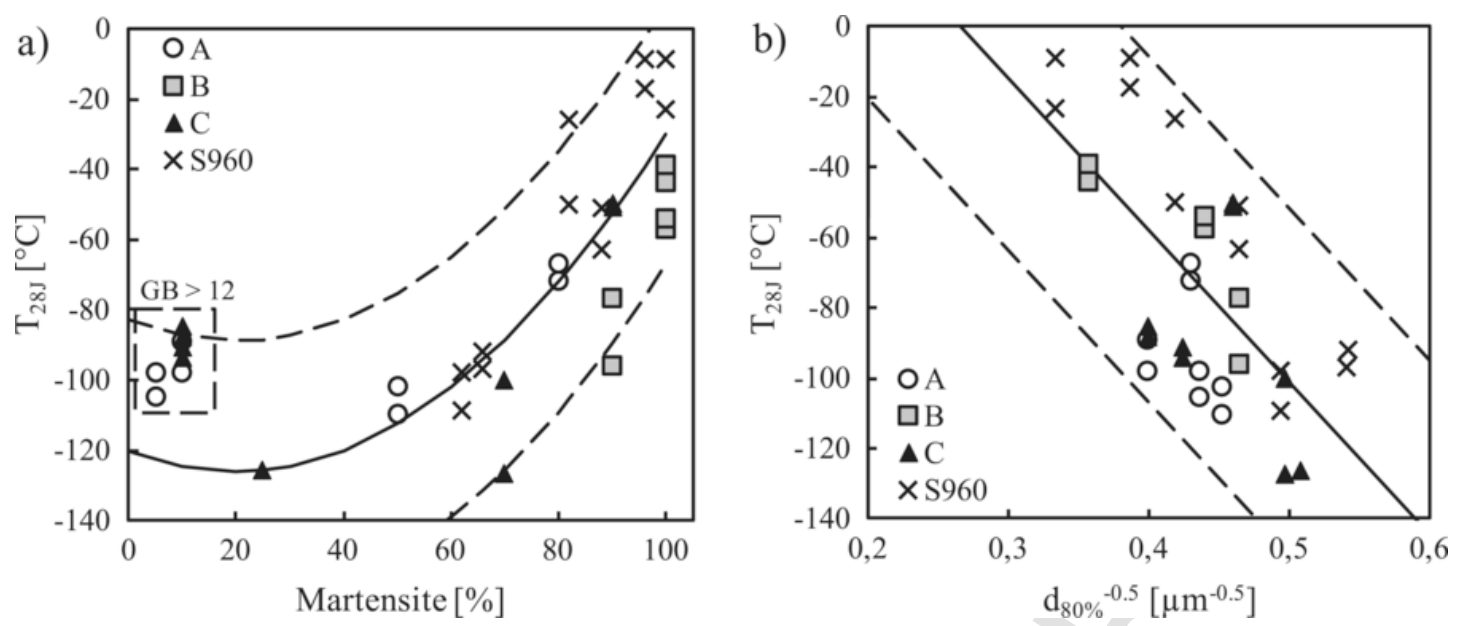

Fig. 3. Changes in $\mathrm{T}_{28 \mathrm{~J}}$ as a function of a) martensite fraction $\mathrm{b}$ ) the inverse square root of the coarse grain size $\mathrm{d}_{80 \%}$ with their corresponding $95 \%$ confidence limits.

\subsection{Correlations}

A study of the influence of individual microstructural and mechanical factors on the impact toughness transition temperature $T_{28 \mathrm{~J}}$ and yield strength is presented in Table 5 considering only the most prominent characteristics and the different grain size definitions. For the analyses, the LT and TL oriented specimen are grouped together due to the similitude of the mechanical properties as shown in Sections 3.1. and 3.2. The bivariate analysis shows martensite fraction (Fig. 3a), coarse grain size (Fig. $3 b), R_{\text {TOT }},\{100\}$ area fraction, and $\sigma_{\mathrm{d}, \text { ref }} \sqrt{ }\left(\pi d_{80 \%}\right)$ to have the biggest influence on $\mathrm{T}_{28 \mathrm{~J}}$ (Table 5). This last term is defined here as the dynamic reference toughness $\left(K_{I d, r e f}\right)$ given in Eq. (3), where room temperature yield strength is elevated to correspond to the dynamic yield strength $\left(\sigma_{\mathrm{d}, \text { ref }}\right)$ at a strain rate of $10^{3} \mathrm{~s}^{-1}$ of a Charpy impact test, and effective coarse grain size $\mathrm{d}_{\text {ecgs }}$ includes $\mathrm{d}_{80 \%}, \mathrm{~d}_{90 \%}$ and $\mathrm{d}_{\mathrm{v}}$ as potential descriptors. For $\sigma_{\mathrm{YS}} \geq 900 \mathrm{MPa}$ and A820 a coefficient $\mathrm{c}_{\sigma \mathrm{YS}}$ of 1.2 is used according to the Ref. [41]. As expected, the grain size descriptors $\mathrm{d}_{80 \%}, \mathrm{~d}_{90 \%}$ and $\mathrm{d}_{\mathrm{v}}$ influence $\mathrm{T}_{28 \mathrm{~J}}$ with little difference observed between them while the average grain size shows the least correlation with $\mathrm{T}_{28 \mathrm{~J}}$.

Contrary to previous studies, no direct relation between the yield strength and impact toughness transition temperatures is observed within the albeit limited yield strength span of $326 \mathrm{MPa}$. The variance in $\mathrm{T}_{28 \mathrm{~J}}$ is explained significantly better when the factors of effective coarse grain size and dynamic yield strength are combined in $\mathrm{K}_{\mathrm{Id} \text {,ref }}$ than with $\mathrm{d}_{\mathrm{ecgs}}$ alone. These findings support the establishment of $\mathrm{K}_{\mathrm{Id} \text {,ref }}$. In general, the parameters that correlate with $\mathrm{T}_{28 \mathrm{~J}}$ do not correlate with room temperature yield strength apart from the martensite fraction.

Linear regression analyses for $\mathrm{T}_{27 \mathrm{~J}}, \mathrm{~T}_{28 \mathrm{~J}}$ and $\mathrm{T}_{50}$, including various combinations of the parameters shown in Table 5 were explored. As discussed below, for all transition temperatures, the statistically most robust result was obtained by combining the reference toughness $\mathrm{K}_{\mathrm{Id} \text {,ref }}$ and the fraction of $\{100\}$ cleavage planes close to the macroscopic crack growth planes in the CVN specimen as given in Eq. (4), where $\mathrm{T}_{\mathrm{T}}$ covers $\mathrm{T}_{27 \mathrm{~J}}, \mathrm{~T}_{28 \mathrm{~J}}$ and $\mathrm{T}_{50}$.

$$
\begin{aligned}
& K_{I d, r e f}[M P a \sqrt{m}]=\sigma_{d, r e f} \sqrt{\pi a}=\left(c_{\sigma Y S} \times \sigma_{Y S}\right) \sqrt{\pi d_{e c g s}} \\
& T_{T}\left[{ }^{\circ} \mathrm{C}\right]=c_{1} \times K_{I d, r e f}+c_{2} \times \%\{100\}+c_{3}
\end{aligned}
$$

\section{Discussion \\ 4.1. Toughness and strength}

From the results, it is evident that the effective coarse grain size $\mathrm{d}_{\text {ecgs }}\left(\mathrm{d}_{80 \%}, \mathrm{~d}_{90 \%}\right.$ or $\left.\mathrm{d}_{\mathrm{v}}\right)$ has a great influence on the transition temperature toughness properties. This is reasonable considering the fact that the probable larger grains eventually sampled in the fracture process zone will most readily cause a cleavage crack to nucleate and propagate over the first grain boundaries. Coarse grain size $\mathrm{d}_{80 \%}$ has a slightly higher correlation to $\mathrm{T}_{28 \mathrm{~J}}$ over the whole population and has therefore been used in the analyses. As a single descriptor, coarse grain size $d_{90 \%}$ and volume-weighted average grain size $d_{v}$ can be also used with reservations. Compared to many studies in the literature, the present data only covers a relatively narrow range of grain sizes, but they do represent a realistic industrially producible range. Refining the prior austenite grains is an effective way to get smaller effective grain size and hence better toughness properties, as is well known from the literature. However, significant improvements are only gained with austenite pancaking, as is shown here with the materials with low finish rolling temperature and high $\mathrm{R}_{\mathrm{TOT}}$. The minimum effective coarse grain size is achieved in the studied materials with the lowest finish rolling

Table 5

\begin{tabular}{|c|c|c|c|c|c|c|c|c|c|c|}
\hline $\mathrm{n}=36$ & & $\begin{array}{l}\mathrm{d}_{\mathrm{avg}}-0.5 \\
{[\mu \mathrm{m}]}\end{array}$ & $\begin{array}{l}\mathrm{d}_{80 \%}{ }^{-0.5} \\
{[\mu \mathrm{m}]}\end{array}$ & $\begin{array}{l}\mathrm{d}_{90 \%}{ }^{-0.5} \\
{[\mu \mathrm{m}]}\end{array}$ & $\begin{array}{l}\mathrm{d}_{\mathrm{v}}^{-0.5} \\
{[\mu \mathrm{m}]}\end{array}$ & $\begin{array}{l}\text { ATM } \\
{[\%]}\end{array}$ & $\mathrm{R}_{\mathrm{TOT}}$ & $\begin{array}{l}\sigma_{\mathrm{YS}} \\
{[\mathrm{MPa}]}\end{array}$ & $\begin{array}{l}\sigma_{\mathrm{d}, \mathrm{ref}} \sqrt{ }\left(\pi \mathrm{d}_{80 \%}\right) \\
{[\mathrm{MPa} \sqrt{ } \mathrm{m}]}\end{array}$ & $\begin{array}{l}\{100\} \text { on crack } \\
\text { plane }[\%]\end{array}$ \\
\hline \multirow[t]{2}{*}{$\mathrm{T}_{28 \mathrm{~J}}$} & $\mathrm{R}^{2}$ & 0.29 & 0.45 & 0.40 & 0.40 & 0.46 & 0.63 & 0.03 & 0.70 & 0.34 \\
\hline & $\mathrm{p}$ & $<0.001$ & $<0.001$ & $<0.001$ & $\begin{array}{l}< \\
0.001\end{array}$ & $\begin{array}{l}< \\
0.001\end{array}$ & $\begin{array}{l}< \\
0.001\end{array}$ & 0.29 & $<0.001$ & $<0.001$ \\
\hline \multirow[t]{2}{*}{$\sigma_{\mathrm{YS}}$} & $\mathrm{R}^{2}$ & 0.18 & 0.19 & 0.21 & 0.21 & 0.40 & 0.02 & & 0.05 & 0.07 \\
\hline & $\mathrm{p}$ & 0.01 & 0.01 & 0.01 & 0.01 & $\begin{array}{l}< \\
0.001\end{array}$ & 0.47 & & 0.19 & 0.12 \\
\hline
\end{tabular}

Correlation of $\mathrm{T}_{28 \mathrm{~J}}$ and yield strength $\left(\sigma_{\mathrm{YS}}\right)$ with selected parameters. 
temperature that still does not cause the formation of granular bainite in significant amounts (i.e. $>10 \%$ ).

The importance of the coarsest grains in the effective grain size distribution in the ductile-brittle transition temperature region can be linked to the double-barrier model as presented by Lambert-Perlade et al. [11]. The critical event for the (local) brittle failure in the propagation-controlled cleavage cracking temperature range is the propagation of a microcrack through the high-angle grain boundaries (matrix-matrix interfaces) of a sufficiently sized grain. Assuming a Griffith criterion for a penny-shaped crack ahead of a macroscopic crack tip and an effective surface energy of $100 \mathrm{~J} / \mathrm{m}^{2}$ [42], $\mathrm{d}_{80 \%}$ between 3.4 and $9.0 \mu \mathrm{m}$ would yield failure stresses in the range $4500 \ldots 2770 \mathrm{MPa}$. This can be considered reasonable as these $\sigma_{\mathrm{f}}$ correspond on average to the case of critical opening stress $\sigma_{\mathrm{f}} \approx(3.0 \pm 0.1) \sigma_{\mathrm{d} \text {,ref }}$, matching with the small-scale yielding condition.

The current approach still neglects the possible effect of inclusions: it has been shown that, in addition to large grains, large inclusions or inclusion clusters can also be the cause of cleavage initiation and alter this result [43-46]. In support for the importance of the discussed size range, the majority of large inclusions fall in to the same $[42,44,45]$, hence potentially making the statistically probable most easily acrossable interface of a large unit the weakest link.

History continues to repeat itself in the sense that material with higher martensite content possesses higher ductile-brittle transition temperatures. However, the direct-quenched and untempered fully martensitic steels B920 and B880 possess moderate low-temperature toughness properties with $\mathrm{T}_{28 \mathrm{~J}}$ at or below $-40{ }^{\circ} \mathrm{C}$, which is $20-30{ }^{\circ} \mathrm{C}$ lower than that of reheated and quenched S960-RQ due to the difference in the sizes of the coarsest grains surrounded by high-angle boundaries, i.e. the differences in $\mathrm{d}_{\text {ecgs. }}$. The best toughness and toughness-strength combination was achieved in steel C with a martensite content of $25 \%$ (C840) and 70\% (C880) while close behind are materials with 50\% and $62 \%$ martensite (A880, S960-820, S960-830). This is in line with previous studies that have shown the benefits of mixed martensite - bainite microstructures [15-17], although the beneficial contribution to toughness was largely attributed to the finer effective grain size compared to ferritic microstructure, whereas in this study the smallest effective grain size in each material is found in the mixed microstructures.

Deformation below $\mathrm{T}_{\mathrm{NR}}$ affects the diffusion-controlled phase transformation and the extent of this effect depends on the hardenability of the steel (Fig. 1a). Both increasing $\mathrm{R}_{\mathrm{TOT}}$ and $\mathrm{FRT}_{\mathrm{N}}$ promote bainite formation. This is especially seen with the materials with the highest $\mathrm{FRT}_{\mathrm{N}}$ (i.e. lowest finish rolling temperature) having formed granular

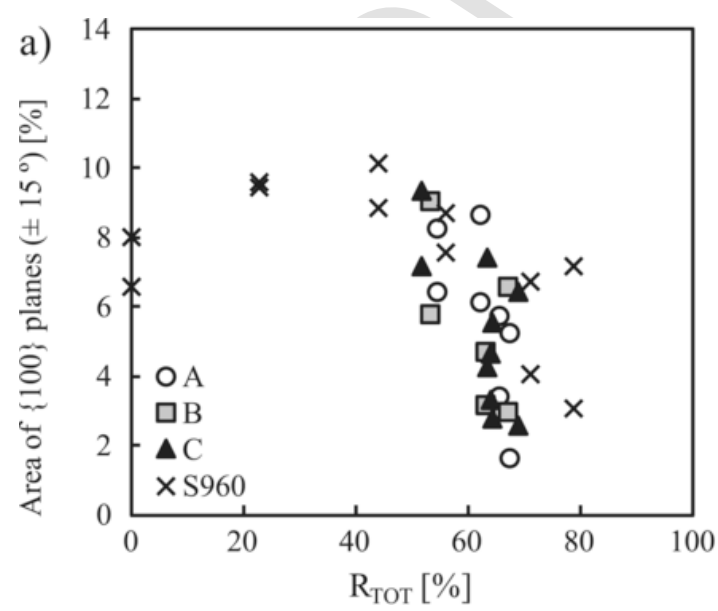

bainite whereas the steels with $\mathrm{FRT}_{\mathrm{N}}$ below 0.05 show lower bainite. The harmful effect of GB is linked to its higher effective grain size [17] due to its subgrain structure consisting of low-angle boundaries, as opposed to the lath-like lower bainite and martensite, and to its M-A constituent islands that are coarser than those in lath-like bainite and martensite [47]. In general, bainite formed at higher temperatures contains more ineffective low-angle boundaries [26]. The presence of more than $10-12 \%$ GB leads to larger effective grain sizes and higher ductile-brittle transition temperatures, but also lower strength, and elevated upper shelf toughness.

Textural evolution, measured from the RD-ND surface for both longitudinal and transverse crack planes, is related to the level of pancaking of the prior austenite grains $[29,48,49]$ : pancaking increases the intensities of the $\sim\{554\}<225>_{\alpha}, \sim\{112\}<110>_{\alpha}$ and $\sim\{112\}<131>_{\alpha}$ texture components at the centreline. Of these, the first one is close to the $\{332\}<113>$ component that can reduce the amount of undesirable $\{100\}<011>[50]$. The decrease in the area fraction of $\{100\}$ planes and the increase in the area fraction of $\{112\}$ planes follow $\mathrm{R}_{\text {TOT }}$ (Fig. 4a). The lower incidence of $\{100\}$ planes close to the crack plane of the Charpy specimen translates similarly to improvement in $\mathrm{T}_{28 \mathrm{~J}}$ (Fig. $4 \mathrm{~b}$ ) as the continuous early cleavage crack propagation is inhibited, although there is clear variance in the effect between the different steels. $\{112\}$ shear planes and the measured texture components $\{001\}<110>$ or $\{112\}<110>$ did not affect the DBTT properties nor the upper shelf toughness, although it can be hypothesised that undefined $\{112\}$ diagonal to crack plane should have more influence at higher temperatures where shearing can play a bigger role in the crack propagation. While $\mathrm{R}_{\mathrm{TOT}}$ affects both the grain size parameters and the amount of $\{100\}$ and $\{112\}$ planes, the latter two have no correlation to each other at all.

The effect of texture on the impact toughness can be illustrated by comparing materials C920 and C840. The pole figures and cropped images from the scanned area showing grains that have $\{100\}$ within \pm $15^{\circ}$ of the RD-ND plane, i.e. the main crack plane of the TL Charpy specimens, are presented in Fig. 5. Due to austenite pancaking there is clear continuous textural banding visible in the rolling direction, as opposed to random distribution found in Ref. [31], which highlights the importance of the reduction of $\{100\}$ fraction to promote crack arrests at the strongest links prevent the crack propagation. The Fig. 5b) and d) clearly show a difference in the size of the grains in which there are cleavage planes within $15^{\circ}$ of the main fracture propagation plane. Between these two, the difference in $\mathrm{T}_{28 \mathrm{~J}}$ is $76{ }^{\circ} \mathrm{C}, 0.51 \mathrm{MPa} \sqrt{\mathrm{m}}$ in $\mathrm{K}_{\mathrm{Id} \text {,ref }}$ and $3.8 \%$ between the area fractions of $\{100\}$ planes. According to Eq. (5) introduced below these values translate to $40{ }^{\circ} \mathrm{C}$ difference in the

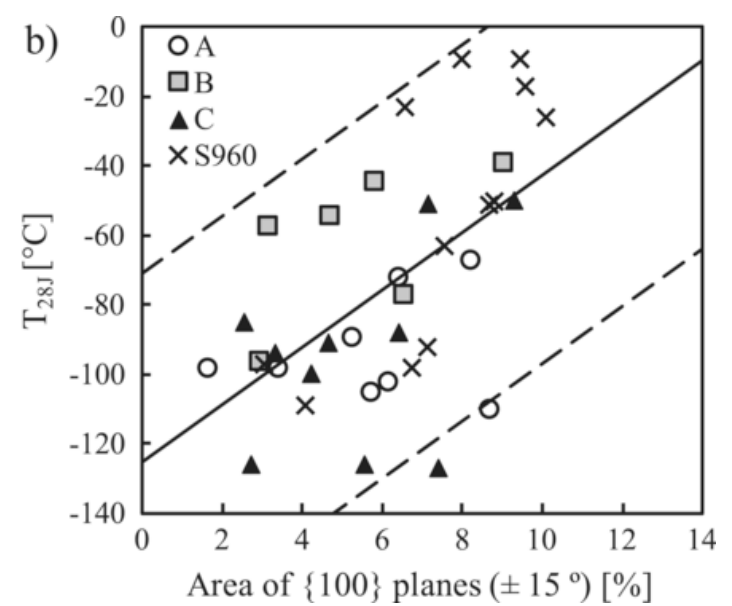

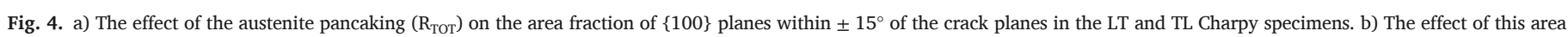
fraction on the impact toughness transition temperatures $\mathrm{T}_{28 \mathrm{~J}}$ of the LT and TL specimens. 


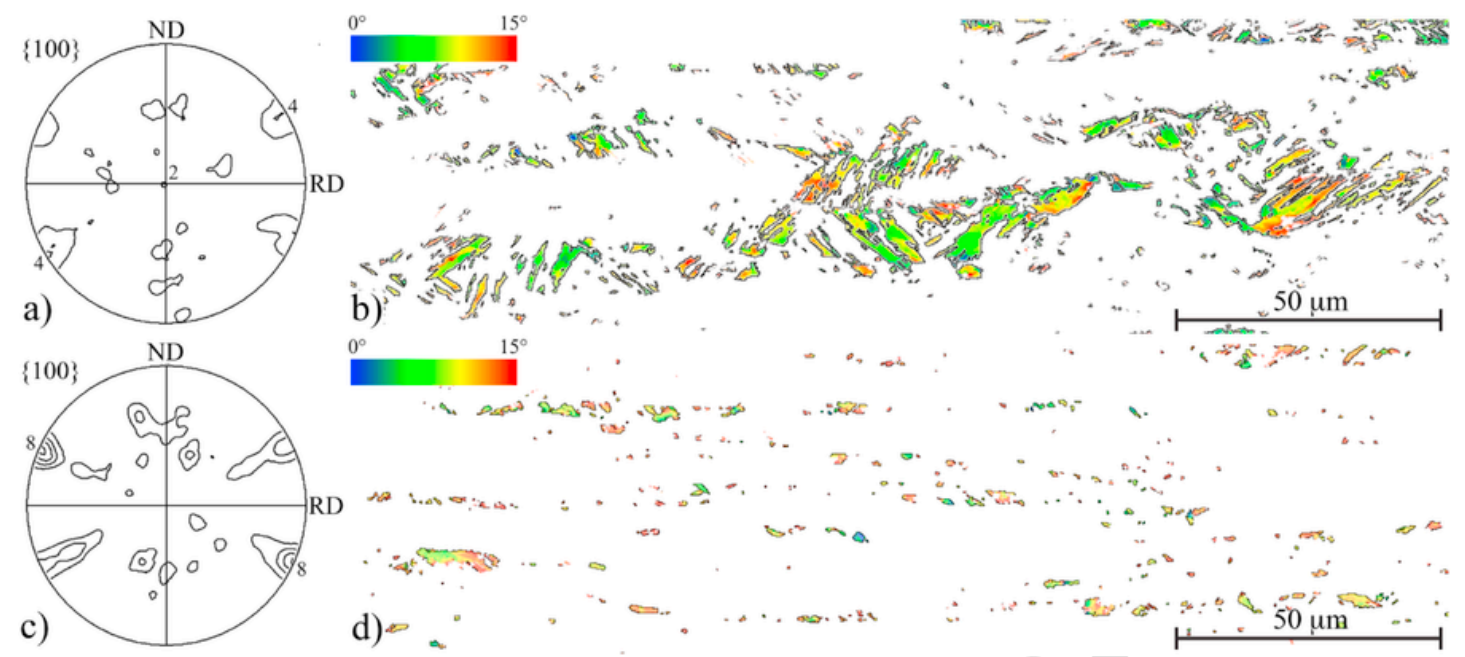

Fig. 5. Pole figures and texture mappings showing grains on the $\{100\}$ plane within $15^{\circ}$ of RD-ND surface of C920 in a) and b), and C840 in c) and d), respectively.

estimated $\mathrm{T}_{28 \mathrm{~J}}$, which still leaves $36^{\circ} \mathrm{C}$ to be explained. These findings are still in line with the finding that a higher density of $\{100\}$ planes parallel to the crack plane led to deteriorated impact toughness [31] (Fig. 4b).

The common presumption that hardened and untempered martensite would be too brittle for structural use is put into a new light when considering the as-quenched low-carbon (C 0.07-0.15 wt\%) ultra-high-strength steels of this study and Ref. [51]: yield strengths range from 849 to $1250 \mathrm{MPa}$ but transition temperatures can be extremely low provided the microstructure is properly controlled by suitable thermomechanical processing (Fig. 6a). The elevating effect of yield strength on DBTT is shown in the correlations of Refs. [9,14,18,21,22]. These formulations stem from studies with ferritic-pearlitic steels, but the yield strength raising effects are undeniable in all the microstructures $[52,53]$.

Fig. 6a) shows the general plot of $\mathrm{T}_{28 \mathrm{~J}}$ versus $\sigma_{\mathrm{YS}}$ with the 53 different steels tested in both LT and TL orientations in this study and in Ref. [51]. The only conclusion what can be drawn from this is that $\mathrm{T}_{28 \mathrm{~J}}$ rarely falls below about $-120{ }^{\circ} \mathrm{C}$ in low-carbon as-quenched steels. No direct relationship between transition temperature and yield stress alone is apparent for these cases. It is necessary to point that this conclusion is dependent on the proper conduction of thermomechanical rolling and quenching process where grain size is kept under control.

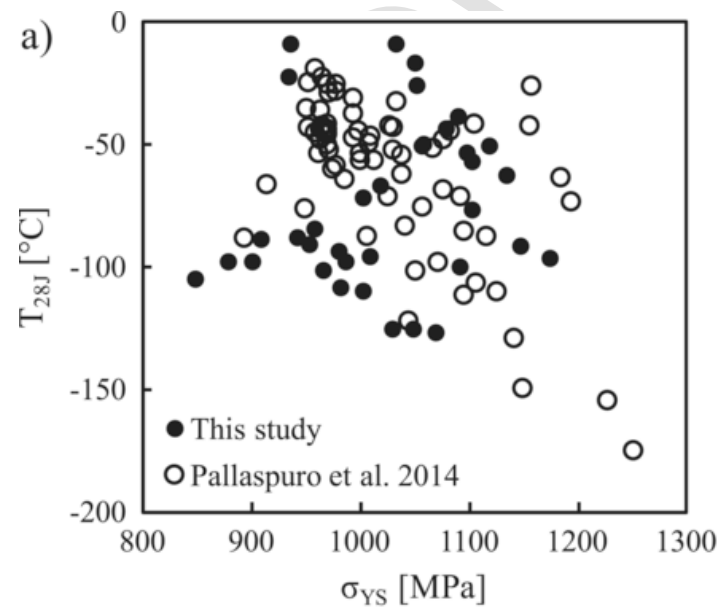

As was shown in Table 5, by combining yield stress with the size of the largest grains in the grain size distributions to form the dynamic reference toughness, $\mathrm{K}_{\mathrm{Id} \text {,ref }}=\sigma_{\mathrm{d} \text {,ref }} \sqrt{ }\left(\pi \mathrm{d}_{\text {ecgs }}\right)$, a strong correlation with $\mathrm{T}_{28 \mathrm{~J}}$ is obtained (Fig. 6b). Similar relationships are found for $\mathrm{T}_{50}$, too. This implies that, in fact, high yield strength and large effective coarse grain size tend to elevate the impact toughness transition temperature values. The correlations between the transition temperatures and the reference toughness imply that there is a stress intensity parameter in the propagation-controlled cleavage fracture process.

\subsection{Transition temperature correlations}

In this study, a new approach was taken to base the model on the combination of microstructural factors that provided a semi-physical estimate of the DBTT with the highest explanatory power that was still statistically robust, i.e. excluding factors that did not yield significant improvement to the model, i.e. hold individual significance. The first term in Eq. (4), $\mathrm{K}_{\mathrm{Id}, \mathrm{ref}}$, can be linked to the initiation of the local cleavage cracks spanning across the coarsest grains and the second term, the fraction of $\{100\}$ planes close to the crack plane, to the propagation and arrest of local cleavage fractures. Since the grain size is measured only on the RD-ND section of the materials, i.e. the fracture lane of the TL specimens, the models are incapable of accounting for the slight grain size related differences in the transition temperatures between

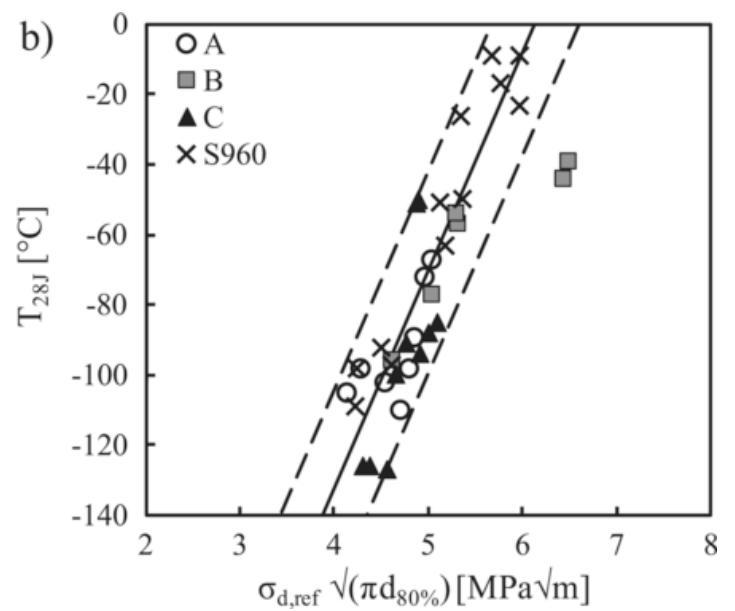

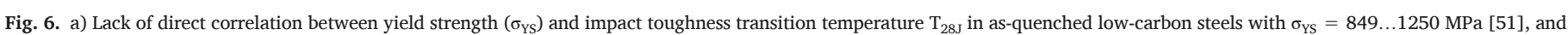
b) the effect of the $\mathrm{K}_{\mathrm{Id}, \text { ref }}$ calculated using the effective coarse grain size $\mathrm{d}_{80 \%}$. 
the LT and TL oriented samples. However, this difference of $4{ }^{\circ} \mathrm{C}$ in $\mathrm{T}_{28 \mathrm{~J}}$, or $6{ }^{\circ} \mathrm{C}$ in $\mathrm{T}_{50}$, can already be explained with the difference in the area of $\{100\}$ planes (Eq. (4)). The influence of the elongated inclusions or inclusions clusters and coarse M-A constituents can too play a role, which ought to be studied further.

Fitting $\mathrm{T}_{28 \mathrm{~J}}$ and $\mathrm{T}_{50}$ to Eq. (3) using $\mathrm{d}_{80 \%}$ as $\mathrm{d}_{\text {ecgs }}$ and excluding the B920 outliers seen in Fig. $6 \mathrm{~b}$ from the data set, we obtain Eq. (5), which has adjusted $\mathrm{R}^{2}=0.83$ and a root mean square error (RMSE) of $14{ }^{\circ} \mathrm{C}$, and Eq. (6), which has adjusted $R^{2}=0.79$ and RMSE $=12{ }^{\circ} \mathrm{C}$, respectively. Note that these equations apply irrespective of the orientation of the test specimen with respect to the rolling direction due to the inclusion of the factor of $\{100\}$ plane fraction in Eq. (4).

It is interesting to compare the values of $\mathrm{T}_{28 \mathrm{~J}}$ and $\mathrm{T}_{50}$ obtained for the present steel microstructures and regression equations with the predictions of the models of Pickering and Gladman [8], Mintz et al. [9] and Gutiérrez [18] that demonstrate the development in different decades (Table 6). For brevity, the Table 6 shows the averages of the experimental and predicted values of $\mathrm{T}_{28 \mathrm{~J}}$ and $\mathrm{T}_{50}$ together with their variances. To estimate the transition temperatures of the materials studied according to the models in Refs. [8,9,18], a conservative value of $\Delta \sigma_{\mathrm{y}}=100 \mathrm{MPa}$ was used in the Gutiérrez model. For the models of Mintz and Gutiérrez, carbide thicknesses of $0.039 \mu \mathrm{m}$ were used for the DQ steels and $0.034 \mu \mathrm{m}$ for the steel S960-RQ [32]. Average grain size $\mathrm{d}_{\mathrm{avg}}$ is used for the three models $[8,9,18]$ as the most favourable. It is clear from Table 6 that, as they are, these earlier models are unable to estimate the DBTT of the studied as-quenched steels. Thorough adjustment of the coefficients and the over-conservative strength terms would be needed for these models to make them usable with the data presented here. Finally, to sum up the goodness of fit of the estimates Eqs. (5) and (6), where $\sigma_{\mathrm{d} \text {,ref }}$ is expressed in MPa and $\mathrm{d}_{80 \%}$ in $\mathrm{m}$, the equations are presented in the Fig. 7a) and b), respectively, with their $95 \%$ confidence limits. To validate the model further, more materials and from a wider range of steel types need to be analysed considering their effective coarse grain sizes and the fractions of $\{100\}$ planes close to the macroscopic crack plane. Widening the yield strength range, es- pecially towards lower strengths, will likely demand adjustment of the yield strength coefficient $\mathrm{c}_{\sigma \mathrm{YS}}$, as shown in Fig. 8.

$$
\begin{aligned}
T_{28 J}\left[{ }^{\circ} \mathrm{C}\right] & =55 \times \sigma_{d, r e f} \sqrt{\pi d_{80 \%}}+3 \times \%\{100\}-365, \sigma \\
& = \pm 14^{\circ} \mathrm{C} \\
T_{50}\left[{ }^{\circ} \mathrm{C}\right] & =42 \times \sigma_{d, r e f} \sqrt{\pi d_{80 \%}}+2 \times \%\{100\}-283, \sigma \\
& = \pm 12^{\circ} \mathrm{C}
\end{aligned}
$$

\section{Conclusions}

A group of martensitic and martensitic-bainitic direct-quenched steels have been studied with relations between the microstructure and impact toughness in mind. Despite their high yield strengths, in the range $850-1175 \mathrm{MPa}$, it has been clearly shown that these ultra-high-strength steels can possess sufficient low-temperature toughness for structural use also in cold regions. The best toughness and toughness - strength combinations are achieved with roughly equal fractions of lath-martensite and bainite in the microstructure, which coincides with the finest effective grain sizes, by utilising maximum austenite pancaking and the lowest finish rolling temperature that still avoid excessive formation of granular bainite. The formation of more than $10 \%$ of granular bainite impairs the toughness and strength because it coarsens the effective grain size.

Analysis of an extended data set of 53 different ultra-high-strength steels with yield strengths between 849 and $1250 \mathrm{MPa}$ revealed no direct correlation between the impact toughness transition temperature and $\sigma_{\mathrm{YS}}$ alone. However, the effect of yield strength is apparent when it is combined with the size of the coarsest grains in the effective grain size distribution $\left(\mathrm{d}_{80 \%}\right)$ to form a dynamic reference toughness $\mathrm{K}_{\mathrm{Id}, \mathrm{ref}}=$ $\sigma_{d, r e f} \sqrt{\pi d_{80 \%}}$. In this work, $d_{80 \%}$, i.e. the effective grain size at $80 \%$ in the cumulative size distribution, was found to be the best way of describing the effective coarse grain size $d_{\text {ecgg, }}$, i.e. the critical unit size

\begin{tabular}{|c|c|c|c|c|c|c|c|}
\hline $\mathrm{n}=34$ & $\begin{array}{l}\text { Experimental } \\
\mathrm{T}_{28 \mathrm{~J}}\end{array}$ & $\begin{array}{l}\text { Experimental } \\
\mathrm{T}_{50}\end{array}$ & $\begin{array}{l}\mathrm{T}_{27 \mathrm{~J}} \text { (Mintz et al. } \\
{[9] \text { ) }}\end{array}$ & $\begin{array}{l}\mathrm{T}_{50} \text { (Pickering \& Gladman } \\
{[8] \text { ) }}\end{array}$ & $\begin{array}{l}\mathrm{T}_{50} \text { (Gutiérrez } \\
{[18] \text { ) }}\end{array}$ & $\begin{array}{l}\mathrm{T}_{28 \mathrm{~J}}, \text { Eq. } \\
(5)\end{array}$ & $\begin{array}{l}\mathrm{T}_{50} \text {, Eq. } \\
(6)\end{array}$ \\
\hline $\begin{array}{l}\text { Average } \\
{\left[{ }^{\circ} \mathrm{C}\right]}\end{array}$ & -77 & -61 & 63 & -21 & 54 & -76 & -62 \\
\hline Variance & 1118 & 699 & 221 & 0 & 8 & 933 & 525 \\
\hline
\end{tabular}
for cleavage fracture. More detailed analysis shows that both impact

Table 6

Experimental average values and variances of $\mathrm{T}_{28 \mathrm{~J}}$ and $\mathrm{T}_{50}$ compared with the estimates from models in the literature and the regression models of this study.
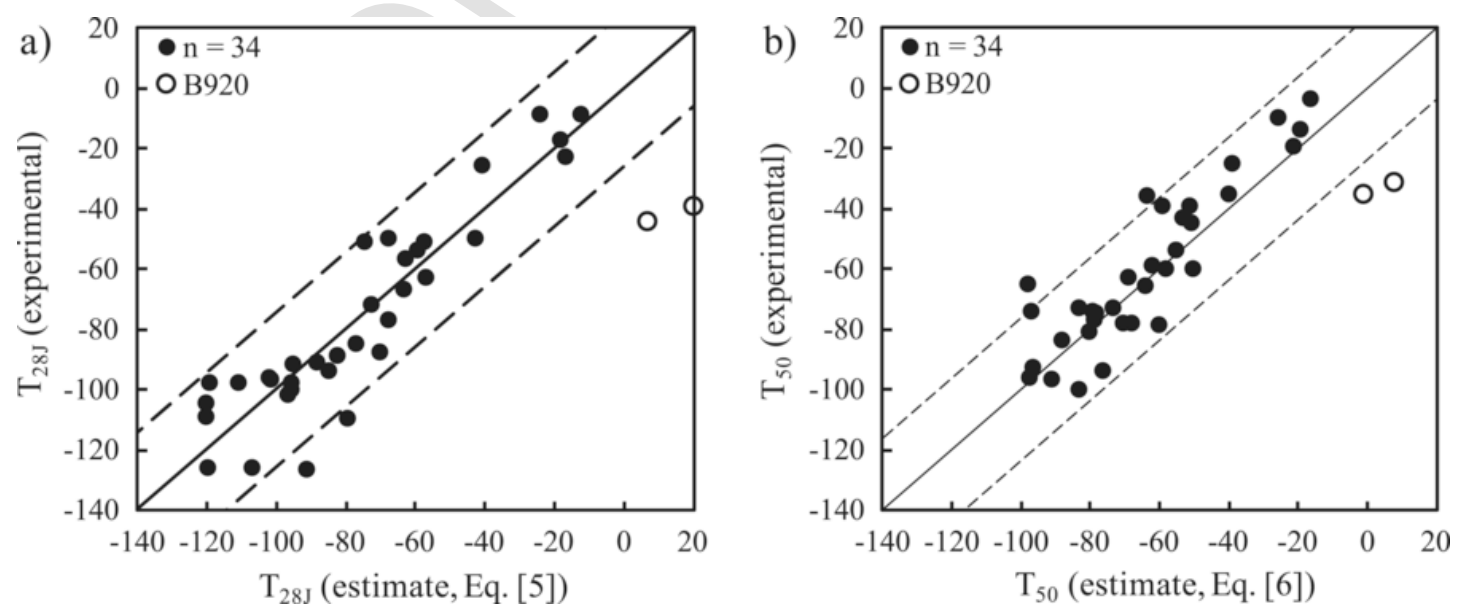

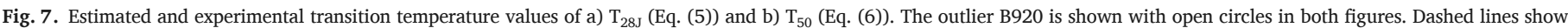
$95 \%$ confidence limits. 


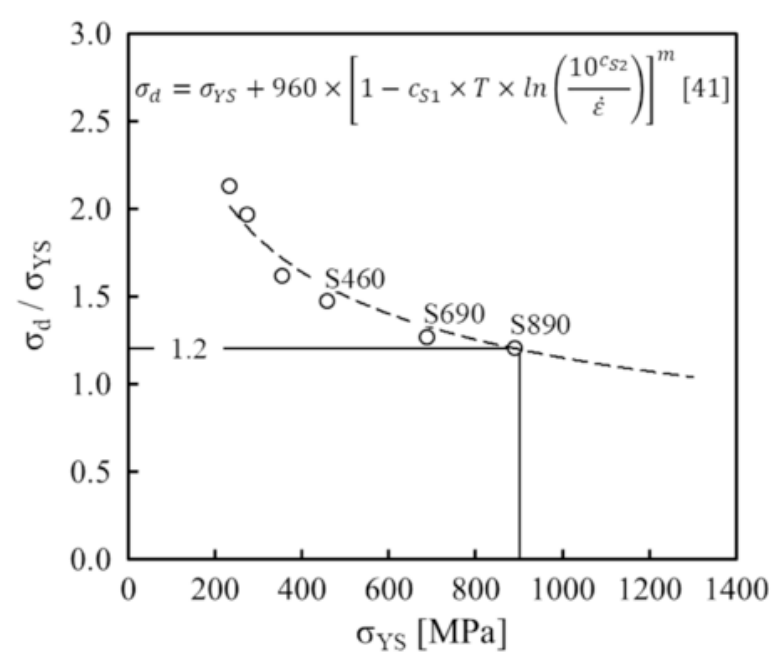

Fig. 8. The basis for the selection of yield strength coefficient $c_{\sigma Y S}$ in Eq. (3) after Ref. [41].

toughness transition temperatures, $\mathrm{T}_{28 \mathrm{~J}}$ and $\mathrm{T}_{50}$, of the as-quenched steels are effectively described by also including the fraction of $\{100\}$ cleavage planes within $15^{\circ}$ of the crack plane of the Charpy V specimen to the model. A high area fraction of $\{100\}$ planes oriented close to the crack plane is detrimental to the low-temperature toughness properties of the steels and the best way to reduce the fraction is extensive rolling below the austenite recrystallisation temperature prior to direct quenching, i.e. austenite pancaking. A high degree of austenite pancaking, i.e. a high $R_{T O T}$, is also an effective way to reduce the grain size including the size of the coarsest grains, e.g. $\mathrm{d}_{80 \%}$.

\section{Acknowledgement}

This work has been done as a part of a doctoral project within the BSA programme of DIMECC Ltd. Funding from the Finnish Funding Agency for Innovation (Tekes) and the participating companies is gratefully acknowledged. Sakari Pallaspuro would also like to thank the Association of Finnish Steel and Metal Producers, Tekniikan edistämissäätiö (TES) and the University of Oulu Graduate School for financially supporting the visit to NTNU, and SSAB for the support provided and the material studied.

\section{References}

[1] K. Wallin, Fracture Toughness of Engineering Materials - Estimation and Application, EMAS Publishing, Warrington, 2011.

[2] ASTM International, E1921-14a: Standard Test Method for Determination of Reference Temperature, T0, for Ferritic Steels in the Transition Range, 2015. 〈http://dx. doi.org/10.1520/E1921-05>.

[3] FITNET, FITNET Fitness-for-Service (FFS) - Procedure (Volume I), Revision M, European Thematic Network FITNET, Geesthacht, 2008.

[4] SINTAP, Structural Integrity Assessment Procedures for European Industry - Final Procedure, Report No. BE95-1426/FR/7, 1999.

[5] CEN, EN 1993-1-10, Eurocode 3: Design of steel structures - Part 1-10: Material toughness and Through-thickness Properties, 2005.

[6] Eurocode 3 - Design of Steel Structures Part 1-12, EN 1993-1-12, Additional Rules for the Extension of EN 1993 up to Steel Grades S 700, 2007.

[7] W. Barr, C. Tipper, Brittle fracture in mild-steel plates, J. Iron Steel Inst. 157 (1947) 223.

[8] F.B. Pickering, T. Gladman, Metallurgical developments in carbon steels, Iron Steel Inst. Spec. Rep. 81 (1963) 10-25.

[9] B. Mintz, G. Peterson, A. Nassar, Structure-property relationships in ferrite-pearlite steels, Ironmak, Steelmak 21 (1994) 215-222.

[10] T. Hanamura, F. Yin, K. Nagai, Ductile-brittle transition temperature of ultrafine ferrite/cementite microstructure in a low carbon steel controlled by effective grain size, ISIJ Int. 44 (2004) 610-617, https://doi.org/10.2355/isijinternational.44. 610.

[11] A. Lambert-Perlade, A.F. Gourgues, J. Besson, T. Sturel, A. Pineau, Mechanisms and modeling of cleavage fracture in simulated heat-affected zone microstructures of a high-strength low alloy steel, Metall. Mater. Trans. A 35 (2004) 1039-1053, https://doi.org/10.1007/s11661-004-1007-6.

[12] C. Wang, M. Wang, J. Shi, W. Hui, H. Dong, Effect of microstructural refinement on the toughness of low carbon martensitic steel, Scr. Mater. 58 (2008) 492-495, https://doi.org/10.1016/j.scriptamat.2007.10.053.

[13] J.W. Morris Jr., On the ductile-brittle transition in lath martensitic steel, ISIJ Int. 51 (2011) 1569-1575, https://doi.org/10.2355/isijinternational.51.1569.

[14] D. Bhattacharjee, J.F. Knott, C.L. Davis, Charpy-impact-toughness prediction using an 'effective' grain size for thermomechanically controlled rolled microalloyed steels, Metall. Mater. Trans. A. 35 (2004) 121-130, https://doi.org/10.1007/ s11661-004-0115-7.

[15] B. Hwang, C.G. Lee, T.-H. Lee, Correlation of microstructure and mechanical properties of thermomechanically processed low-carbon steels containing boron and copper, Metall. Mater. Trans. A. 41 (2010) 85-96, https://doi.org/10.1007/ s11661-009-0070-4.

[16] B. Hwang, C.G. Lee, S.-J. Kim, Low-temperature toughening mechanism in thermomechanically processed high-strength low-alloy steels, Metall. Mater. Trans. A 42 (2011) 717-728, https://doi.org/10.1007/s11661-010-0448-3.

[17] H.K. Sung, S.Y. Shin, B. Hwang, C.G. Lee, S. Lee, Effects of B and Cu addition and cooling rate on microstructure and mechanical properties in low-carbon, high-strength bainitic steels, Metall. Mater. Trans. A. 43 (2012) 3703-3714, https: //doi.org/10.1007/s11661-012-1183-8.

[18] I. Gutiérrez, Effect of microstructure on the impact toughness of Nb-microalloyed steel: generalisation of existing relations from ferrite-pearlite to high strength $\mathrm{mi}$ crostructures, Mater. Sci. Eng. A. 571 (2013) 57-67, https://doi.org/10.1016/j. msea.2013.02.006.

[19] J.W. Morris, C. Kinney, K. Pytlewski, Y. Adachi, Microstructure and cleavage in lath martensitic steels, Sci. Technol. Adv. Mater. 14 (2013) 14208, https://doi.org/ 10.1088/1468-6996/14/1/014208.

[20] A.J. Kaijalainen, P.P. Suikkanen, T.J. Limnell, L.P. Karjalainen, J.I. Kömi, D.A. Porter, Effect of austenite grain structure on the strength and toughness of direct-quenched martensite, J. Alloy. Compd. 577 (2013) S642-S648, https://doi. org/10.1016/j.jallcom.2012.03.030.

[21] N. Isasti, D. Jorge-Badiola, M.L. Taheri, P. Uranga, Microstructural features controlling mechanical properties in Nb-Mo microalloyed steels. Part II: impact toughness, Metall. Mater. Trans. A. 45 (2014) 4972-4982, https://doi.org/10.1007/ s11661-014-2451-6.

[22] T. Jia, Y. Zhou, X. Jia, Z. Wang, Effects of microstructure on CVN impact toughness in thermomechanically processed high strength microalloyed steel, Metall. Mater. Trans. A. 48 (2016) 685-696, https://doi.org/10.1007/s11661-016-3893-9.

[23] J. Han, A.K. da Silva, D. Ponge, D. Raabe, S.-M. Lee, Y.-K. Lee, S.-I. Lee, B. Hwang, The effects of prior austenite grain boundaries and microstructural morphology on the impact toughness of intercritically annealed medium Mn steel, Acta Mater. 122 (2017) 199-206, https://doi.org/10.1016/j.actamat.2016.09.048.

[24] H. Terasaki, Y. Miyahara, M. Ohata, K. Moriguchi, Y. Tomio, K. Hayashi, Visualization of microstructural factor resisting the cleavage-crack propagation in the simulated heat-affected zone of bainitic steel, Metall. Mater. Trans. A 46 (2015) 5489-5493, https://doi.org/10.1007/s11661-015-3167-y.

[25] S. Morito, X. Huang, T. Furuhara, T. Maki, N. Hansen, The morphology and crystallography of lath martensite in alloy steels, Acta Mater. 54 (2006) 5323-5331, https://doi.org/10.1016/j.actamat.2006.07.009.

[26] T. Furuhara, H. Kawata, S. Morito, T. Maki, Crystallography of upper bainite in Fe-Ni-C alloys, Mater. Sci. Eng. A 431 (2006) 228-236, https://doi.org/10.1016/j. msea.2006.06.032.

[27] B. Hutchinson, J. Hagström, O. Karlsson, D. Lindell, M. Tornberg, F. Lindberg, M. Thuvander, Microstructures and hardness of as-quenched martensites $(0.1-0.5 \% \mathrm{C})$, Acta Mater. 59 (2011) 5845-5858, https://doi.org/10.1016/j.actamat.2011.05. 061.

[28] J. Hannula, J. Kömi, D.A. Porter, M.C. Somani, A. Kaijalainen, P. Suikkanen, J.-R. Yang, S.-P. Tsai, Effect of boron on the strength and toughness of direct-quenched low-carbon niobium bearing ultra-high-strength martensitic steel, Metall. Mater. Trans. A (2017) 1-13, https://doi.org/10.1007/s11661-017-4295-3.

[29] A.J. Kaijalainen, P. Suikkanen, L.P. Karjalainen, J.J. Jonas, Effect of austenite pancaking on the microstructure, texture, and bendability of an ultrahigh-strength strip steel, Metall. Mater. Trans. A 45 (2014) 1273-1283, https://doi.org/10.1007/ s11661-013-2062-7.

[30] A. Kaijalainen, Effect of Microstructure on the Mechanical Properties and Bendability of Direct-quenched Ultrahigh-strength Steels, University of Oulu, 2016.

[31] P. Yan, O.E. Güngör, P. Thibaux, M. Liebeherr, H.K.D.H. Bhadeshia, Tackling the toughness of steel pipes produced by high frequency induction welding and heat-treatment, Mater. Sci. Eng. A 528 (2011) 8492-8499, https://doi.org/10. 1016/j.msea.2011.07.034.

[32] A. Kaijalainen, S. Pallaspuro, D. a. Porter, Tempering of direct quenched low-alloy ultra-high-strength steel, Part I - microstructure, Adv. Mater. Res. 922 (2014) 316-321, https://doi.org/10.4028/www.scientific.net/AMR.922.316.

[33] P. Lehto, H. Remes, T. Saukkonen, H. Hänninen, J. Romanoff, Influence of grain size distribution on the Hall-Petch relationship of welded structural steel, Mater. Sci. Eng. A 592 (2014) 28-39, https://doi.org/10.1016/j.msea.2013.10.094.

[34] A. Pineau, A. Benzerga, T. Pardoen, Overview article failure of metals I - brittle and ductile fracture, Acta Mater. 107 (2016) 424-483.

[35] J. Kömi, P. Karjalainen, D. Porter, Direct-quenched structural steels, in: Encycl. Iron, Steel, Their Alloy., CRC Press, 2016, pp. 1109-1125. 〈http://dx.doi.org/10. 1081/E-EISA-120049737〉. 
[36] British Standards Institution Welding: Recommendations for Welding of Metallic Materials, Part 2: Arc Welding of Ferritic Steels British Standards Institution 2001

[37] T.M. Maccagno, J.J. Jonas, S. Yue, B.J. McCrady, R. Slobodian, D. Deeks, Determination of recrystallization stop temperature from rolling mill logs and comparison with laboratory simulation results, ISIJ Int. 34 (1994) 917-922, https://doi.org/ 10.2355/isijinternational.34.917.

[38] R.L. Higginson, C.M. Sellars, Worked Examples in Quantitative Metallography 1st ed., CRC Press, London, 2003.

[39] G. Krauss, Steels - Processing, Structure, and Performance 2nd ed., ASM International, Materials Park, 2015.

[40] ISO, EN ISO 148-1: Metallic Materials, Charpy pendulum impact test, Part 1: Test Method.

[41] G. Sedlacek, M. Feldmann, B. Kühn, D. Tschickardt, S. Höhler, C. Müller, W. Hensen, N. Stranghöner, W. Dahl, P. Langenberg, S. Münstermann, J. Brozetti, J. Raoul, R. Pope, F. Bijlaard, Commentary and Worked Examples to EN 1993-1-10 Material Toughness and through Thickness Properties" and Other Toughness Oriented Rules in EN 1993, 2008.

[42] J.I. San Martin, J.M. Rodriguez-Ibabe, Determination of energetic parameters controlling cleavage fracture in a Ti-V microalloyed ferrite-pearlite steel, Scr. Mater. 40 (1999) 459-464, https://doi.org/10.1016/S1359-6462(98)00467-9.

[43] X.Z. Zhang, J.F. Knott, Cleavage fracture in bainitic and martensitic microstructures, Acta Mater. 47 (1999) 3483-3495, https://doi.org/10.1016/ S1359-6454(99)00200-1.

[44] A. Ghosh, A. Ray, D. Chakrabarti, C.L. Davis, Cleavage initiation in steel: competition between large grains and large particles, Mater. Sci. Eng. A 561 (2013) 126-135, https://doi.org/10.1016/j.msea.2012.11.019.
[45] J. Du, M. Strangwood, C.L. Davis, Effect of TiN particles and grain size on the Charpy impact transition temperature in steels, J. Mater. Sci. Technol. 28 (2012) 878-888, https://doi.org/10.1016/S1005-0302(12)60146-7.

[46] B. Tanguy, J. Besson, R. Piques, A. Pineau, Ductile to brittle transition of an A508 steel characterized by Charpy impact test Part I: experimental results, Eng. Fract. Mech. 72 (2005) 49-72, https://doi.org/10.1016/j.engfracmech.2004.03.010.

[47] F.G. Caballero, H. Roelofs, S. Hasler, C. Capdevila, J. Chao, J. Cornide, C. Garcia-Mateo, Influence of bainite morphology on impact toughness of continuously cooled cementite free bainitic steels, Mater. Sci. Technol. 28 (2012) 95-102, https: //doi.org/10.1179/1743284710Y.0000000047.

[48] R.K. Ray, J.J. Jonas, Transformation textures in steels, Int. Mater. Rev. 35 (1990) 1-36, https://doi.org/10.1179/095066090790324046.

[49] R.K. Ray, M.P. Butrón-Guillén, J.J. Jonas, G.E. Ruddle, Effect of controlled rolling on texture development in a plain carbon and a $\mathrm{Nb}$ microalloyed steel, ISIJ Int. 32 (1992) 203-212, https://doi.org/10.2355/isijinternational.32.203.

[50] R.D.K. Misra, H. Nathani, F. Siciliano, T. Carneiro, Effect of texture and microstructure on resistance to cracking of high-strength hot-rolled Nb-Ti microalloyed steels, Metall. Mater. Trans. A. 35 (2004) 3024-3029, https://doi.org/10.1007/ s11661-004-0045-4.

[51] S. Pallaspuro, T. Limnell, P. Suikkanen, D. Porter, T0 - T28J correlation of low-carbon ultra-high-strength quenched steels, Procedia Mater. Sci. 3 (2014) 1032-1037.

[52] H.K.D.H. Bhadeshia, Bainite in Steels: Transformations, Microstructure and Properties 2nd ed., IOM Communications Ltd, London, 2001.

[53] D.A. Porter, K.E. Easterling, M.Y. Sherif, Phase Transformations in Metals and Alloys 3rd ed., CRC Press, 2009. 